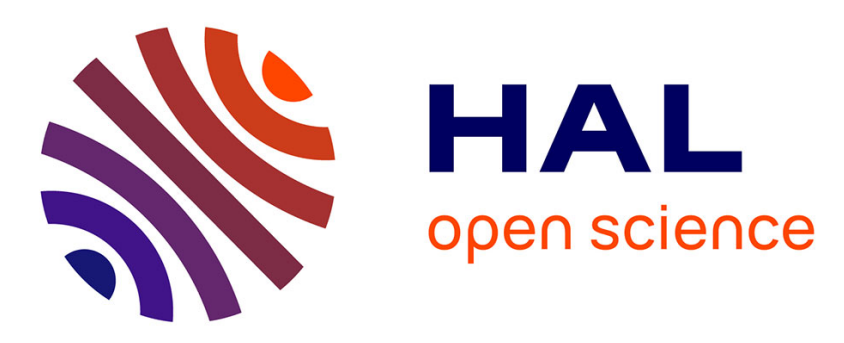

\title{
Chiral Macroporous MOF Surfaces for Electroassisted Enantioselective Adsorption and Separation
}

\author{
Duangkamon Suttipat, Sopon Butcha, Sunpet Assavapanumat, Thana \\ Maihom, Bhavana Gupta, Adeline Perro, Neso Sojic, Alexander Kuhn, \\ Chularat Wattanakit
}

\section{To cite this version:}

Duangkamon Suttipat, Sopon Butcha, Sunpet Assavapanumat, Thana Maihom, Bhavana Gupta, et al.. Chiral Macroporous MOF Surfaces for Electroassisted Enantioselective Adsorption and Separation. ACS Applied Materials \& Interfaces, 2020, 12 (32), pp.36548-36557. 10.1021/acsami.0c09816 . hal-02938171

\section{HAL Id: hal-02938171 \\ https://hal.science/hal-02938171}

Submitted on 14 Sep 2020

HAL is a multi-disciplinary open access archive for the deposit and dissemination of scientific research documents, whether they are published or not. The documents may come from teaching and research institutions in France or abroad, or from public or private research centers.
L'archive ouverte pluridisciplinaire $\mathbf{H A L}$, est destinée au dépôt et à la diffusion de documents scientifiques de niveau recherche, publiés ou non, émanant des établissements d'enseignement et de recherche français ou étrangers, des laboratoires publics ou privés. 


\title{
Chiral Macroporous MOF Surfaces for Electroassisted Enantioselective Adsorption and Separation
}

\author{
Duangkamon Suttipat, ${ }^{\dagger}$ Sopon Butcha, ${ }^{\dagger}{ }^{\ddagger}$ Sunpet Assavapanumat, ${ }^{\dagger,}$ Thana Maihom, ${ }^{\S}$ Bhavana Gupta, ${ }^{\ddagger}$ \\ Adeline Perro, ${ }^{\ddagger}$ Neso Sojic, ${ }^{\ddagger}$ Alexander Kuhn, ${ }^{\ddagger},{ }^{*}$ Chularat Wattanakit ${ }^{\dagger,}$ \\ ${ }^{\dagger}$ School of Energy Science and Engineering, School of Molecular Science and Engineering, and \\ Nanocatalysts and Nanomaterials for Sustainable Energy and Environment Research Network of \\ NANOTEC, Vidyasirimedhi Institute of Science and Technology, Rayong 21210, Thailand
University Bordeaux, CNRS UMR 5255, Bordeaux INP, Site ENSCBP, Pessac, France

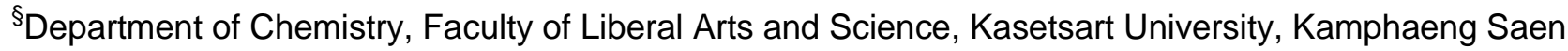 Campus, Nakhon Pathom 73140, Thailand

* Corresponding author. E-mail address: kuhn@enscbp.fr (A. Kuhn), Chularat.W@vistec.ac.th (C. Wattanakit).

KEYWORDS. MOF, electrodeposition, enantioselectivity, macroporous materials, chirality, electrochromatogrphy

\begin{abstract}
The development of surfaces with chiral features is a fascinating challenge for modern material science, especially when they are used for chiral separation technologies. In this contribution, the design of hierarchically structured chiral macroporous ZIF-8 electrodes is presented. They are elaborated by an electrochemical depositiondissolution technique, based on the electrodeposition of metal through a colloidal crystal template, followed by controlled electrooxidation. This generates locally metal cations, which can interact with a chiral ligand present in solution to form Metal-Organic Frameworks (MOFs). The macroporous structure facilitates the access of the chiral recognition sites, located in the mesoporous MOF and thus helps to overcome mass transport limitations. The efficiency of the designed functional materials for chiral adsorption and separation can be fine-tuned by applying an adjustable electric potential to the electrode surfaces. This hierarchical chiral ZIF-8 structure was deposited at the walls of a microfluidic device and used as a stationary phase for enantioselective separation. The potential- controlled interaction between the stationary phase and the chiral analytes allows baseline separation of two enantiomers. This opens up interesting perspectives for using hierarchically structured chiral MOF as an efficient material for the selective adsorption and separation of chiral compounds.
\end{abstract}

\section{Introduction}

The development of chiral materials/compounds is a fascinating topic, especially in the frame of biological and pharmaceutical applications, because only one enantiomer can exhibit a positive biological effect, whereas the other one exhibits no or eventually a negative effect ${ }^{1}$. As a consequence, it is very important to develop functional chiral materials, as they can be used for various potential applications ranging from adsorption ${ }^{2-3}$ to separation ${ }^{3-16}$ and catalysis ${ }^{17}$. In recent years, various approaches have explored solid surfaces with integrated chiral features, obtained by the adsorption of chiral molecules, ${ }^{18-21}$ the binding/grafting of chiral ligands, ${ }^{22}$ the synthesis of intrinsically chiral metals ${ }^{10,17,23-30}$ or chiral porous frameworks, ${ }^{3}$ and the incorporation of chiral ligands inside porous materials. ${ }^{11-16,31}$
Metal-organic frameworks (MOFs) are very useful crystalline hybrid porous materials, based on the coordination chemistry between metal nodes and organic ligands. $^{32-48}$ MOFs have attracted considerable attention in the context of various potential applications ${ }^{32-33}$ such as gas storage, ${ }^{34-35}$ drug delivery, ${ }^{39}$ sensing, ${ }^{40}$ catalysis, ${ }^{38,}{ }^{41-42}$ molecular recognition, ${ }^{43}$ electronics ${ }^{44}$, separation, ${ }^{45}$ and water-gas shift reactions, ${ }^{49}$ due to their unique properties, such as high surface area, crystalline structure and tunable pore size. In addition, it is possible to generate chiral MOF surfaces by introducing chiral ligands. As an example, Slater et al. have successfully synthesized a homochiral metal-organic framework, $\mathrm{Zn}_{2}$ (bdc)(Llac) (dmf) (ZnBLD; bdc = 1,4-benzenedicarboxylic acid, Llac $=\mathrm{L}$-lactic acid, $\mathrm{dmf}=\mathrm{N}, \mathrm{N}^{\prime}$-dimethylformamide) for the enantioselective separation of 1-phenylethanol and 2butanol..$^{50}$ They found that missing linker defects in 
ZnBLD can improve the enantiomeric separation of 1phenylethanol by around $35 \%$. The results clearly demonstrate that chiral MOFs can be obtained by integrating a chiral ligand and used for challenging applications.

Although there are some reports demonstrating the possibility to design chiral MOFs, most of them have a purely microporous structure, which might limit the access of molecules to the active sites due to mass transport limitations. In order to improve the efficiency of conventional MOFs, a lot of effort has been made to design MOFs with a hierarchical pore structure by introducing additional larger pores such as meso- and macropores..$^{5-54}$ Zhang et al. have for example successfully designed hierarchical $\mathrm{Zn} / \mathrm{Ni}-\mathrm{MOF}-2$ nanosheetassembled hollow nanocubes for the alkoxy carbonylation of aryl iodides, resulting in a superior catalytic activity (conversion yield $\sim 70 \%$ )..$^{53}$

It is well-known that several concepts can be applied to synthesize hierarchical MOFs including solvothermal synthesis,,$^{55}$ microwave synthesis ${ }^{56-57}$ and electrochemical methods..$^{58}$ Among them, the electrochemical synthesis of MOFs to generate hierarchical porous structures is a very interesting choice and is still in the early stage of development..$^{59-61}$ Electrochemical concepts have the advantage that the synthesis of MOFs can be carried out under mild conditions (e.g. green solvent, low temperature and pressure), have low operating costs and a short synthesis time. In addition, the electrochemical approach allows controlling precisely the rate of nucleation and crystallization during the MOF formation via the amplitude of the applied potential. For example, hierarchical macro-/microporous HKUST-1 electrodes were obtained by electrochemical synthesis when using silica spheres as colloidal crystal templates to create macroporous $\mathrm{Cu}$, which then can be further transformed into porous MOF by the interaction of ligand and copper ions resulting from the controlled electrodissolution of the electrode. ${ }^{58}$

The chiral character of MOFs can be tuned because chiral ligands can be introduced into the microporous structure. These materials have been used for various applications such as chromatography 3, 11-13, 16, 62${ }^{63}$ and also for asymmetric synthesis ${ }^{64}$ due to their unique crystal structure, flexible composition and tunable chiral active sites. As the above-mentioned hierarchical MOFs have in general a superior performance due to the better accessibility of the internal reaction space, it would be very interesting to combine hierarchically structured porous MOFs and chiral features. However, the design of hierarchical porous MOFs with chiral functionalities has not yet been reported, even though they should have significant benefits for several applications.

Recently, potential induced fine-tuning of the interactions between chiral molecules and a chiral stationary phase has been proposed in the context of separation science. ${ }^{29}$ It was found that chiral imprinted mesoporous Pt films as stationary phase in a hyphenated microfluidic electrochromatography device allow the separation of chiral compounds. Applying a suitable positive potential to the stationary phase leads to baseline separation of a racemic mixture. ${ }^{29}$ In this context, the electrosynthesis of hierarchical macroporous MOFs with chiral features is proposed as a complementary approach. Hierarchical chiral ZIF-8 has been chosen as a model material due to its thermal and chemical stability. In addition, ZIF-8 can be synthesized in a wide range of solvents under mild conditions. ${ }^{65-66}$ The obtained material is tested with respect to its efficiency for enantioselective adsorption and separation. In particular, the hierarchical macroporous chiral MOF has been used as a stationary phase in a microfluidic electrochromatographic device.

\section{Experimental Section}

\subsection{Materials}

For the synthesis of hierarchical macroporous chiral ZIF-8, zinc sulfate heptahydrate $\left(\mathrm{ZnSO}_{4} \cdot 7 \mathrm{H}_{2} \mathrm{O}\right.$ : 99\%, Sigma-Aldrich), 2-methyl imidazolate (2-mIm; 99\%, Sigma-Aldrich), L-histidine (99\%, Sigma-Aldrich) and D-histidine (99\%, Sigma-Aldrich) were used as metal center, original ligand and chiral ligand, respectively. Styrene monomer (TCI), potassium peroxide (KPS), ethyl acetate (Sigma-Aldrich) and ethanol (98\%, SigmaAldrich) were used for the polystyrene bead synthesis. All chemicals were used without further purification.

\subsection{Synthesis of polystyrene (PS) beads}

10 grams of styrene monomer, $62 \mathrm{~mL}$ of ultrapure water $(18.2 \mathrm{M} \Omega \cdot \mathrm{cm})$ and $8 \mathrm{~mL}$ of ethyl acetate were mixed. Then, the mixture was added into a potassium peroxide solution (KPS), and stirred at $70^{\circ} \mathrm{C}$ for 14 hours. Subsequently, the resulting polymer beads were washed with an excess of ethanol and kept in water.

\subsection{Synthesis of flat ZIF-8, chiral flat ZIF-8 and hier- archical macroporous chiral ZIF-8 electrodes}

\subsubsection{Synthesis of flat ZIF-8 and chiral flat ZIF-8 electrodes}

An Au electrode, Pt mesh and a $\mathrm{Ag} / \mathrm{AgCl}$ electrode were used as working, counter and reference electrodes, respectively. The deposition of $\mathrm{Zn}$ was performed in $0.5 \mathrm{M}$ of $\mathrm{ZnSO}_{4}$ solution prepared in $0.05 \mathrm{M} \mathrm{Na}_{2} \mathrm{SO}_{4}$ electrolyte under $\mathrm{N}_{2}$ flow to avoid contamination with oxygen. A negative potential of $-1.08 \mathrm{~V}$ (vs. $\mathrm{Ag} / \mathrm{AgCl}$ ) was applied for $\mathrm{Zn}$ deposition to reduce $\mathrm{Zn}^{2+}$ into metallic $\mathrm{Zn}$. Subsequently, a less negative potential of $-0.70 \mathrm{~V}$ (vs. $\mathrm{Ag} / \mathrm{AgCl}$ ) was applied in a $1 \mathrm{M}$ solution of 2-methyl imidazolate $(2-\mathrm{mlm})$ ligand for $\mathrm{Zn}$ oxidation and formation of ZIF-8. In the case of the synthesis of chiral flat ZIF-8, the chiral ligand, L-histidine or D-histidine ( $\mathrm{lM})$, was added to the $2-\mathrm{mlm}$ solution so that the final concentration of histidine is $0.1 \mathrm{M}$, and the same electrodissolution procedure was followed. 


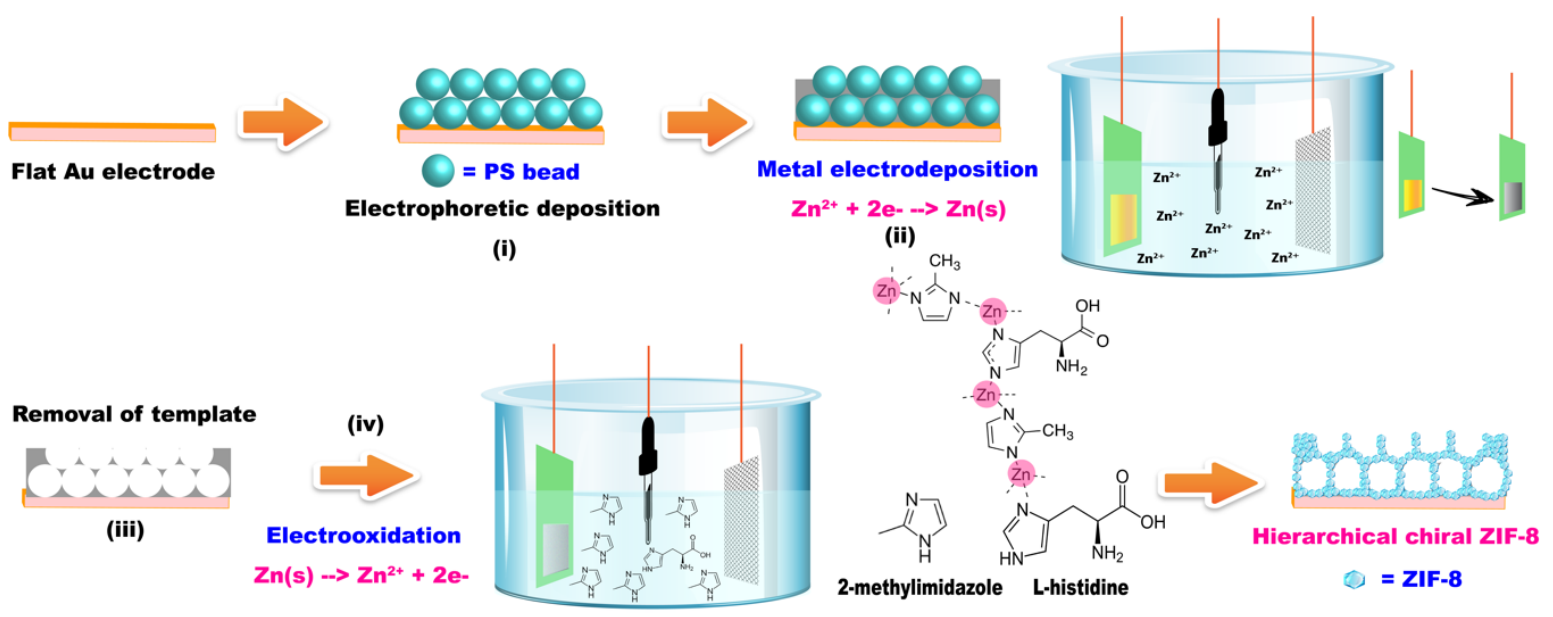

Scheme 1. Illustration of the synthesis steps of hierarchical macroporous chiral ZIF-8 including: (i) PS bead assembly via electrophoretic deposition, (ii) Electrodeposition of macroporous Zn, (iii) Removal of PS beads, (iv) Electrodissolution of $\mathrm{Zn}$ in the presence of the organic ligands.

2.3.2. Synthesis of hierarchical macroporous chiral ZIF-8 electrodes

PS bead template formation by electrophoretic deposition: A suspension of PS beads was prepared with a concentration of $50 \mathrm{mg} / \mathrm{mL}$ in ultrapure water. For the electrophoretic deposition of PS beads on Au electrodes, pulsed electrodeposition was used with an applied potential of $1.8 \mathrm{o} \mathrm{V}$ vs. $\mathrm{Ag} / \mathrm{AgCl}$ (pulse duration and relaxation time of 5 seconds and 20 seconds, respectively). Subsequently, the electrode was heated at $80^{\circ} \mathrm{C}$ for 10 min to ensure that the PS beads stay in a compact arrangement on the $\mathrm{Au}$ electrode surface.

Electrodeposition of macroporous $\mathrm{Zn}$ : For the electrodeposition of $\mathrm{Zn}$ through the PS bead template, a negative potential of $-1.08 \mathrm{~V}$ ( $\mathrm{vs}$. $\mathrm{Ag} / \mathrm{AgCl})$ was applied in order to reduce $\mathrm{Zn}^{2+}$ to metallic $\mathrm{Zn}$ using $0.05 \mathrm{M}$ of $\mathrm{Na}_{2} \mathrm{SO}_{4}$ as supporting electrolyte. In order to obtain macroporous $\mathrm{Zn}$, the PS bead template was removed by immersion in tetrahydrofuran for $15 \mathrm{~min}$.

Electrodissolution of macroporous $\mathrm{Zn}$ to form chiral macroporous MOFs: A potential in the range from -0.7o V to $+0.30 \mathrm{~V}$ (vs. $\mathrm{Ag} / \mathrm{AgCl}$ ) was applied to the $\mathrm{Zn}$ deposit in a mixture of 2-mIm (1M) as original ZIF-8 ligand and D- or L-His as chiral ligand (o.1 M) using $0.05 \mathrm{M}$ of $\mathrm{Na}_{2} \mathrm{SO}_{4}$ as supporting electrolyte. The electrooxidation of $\mathrm{Zn}$ produces $\mathrm{Zn}^{2+}$ ions, which interact with the ligand solution to form a hierarchical chiral ZIF-8 layer (Scheme 1).

\subsection{Characterization and chiral recognition studies}

To investigate the morphology of the designed electrodes, scanning electron microscopy (SEM) images were obtained using a JEOL JSM-7610F microscope with
0.5-2 $\mathrm{kV}$ accelerating voltage. The samples were mounted without metal coating. To confirm the structure of MOFs, powder X-ray diffraction (XRD) patterns were recorded with a Bruker D8 ADVANCE instrument with $0.02^{\circ}$ step size in the $2 \Theta$ range from 5 to $60^{\circ}$ in the thin film mode. In order to confirm the presence of the chiral ligand in the MOF skeleton, the as-synthesized electrodes were characterized by Fourier Transform Infrared (FTIR) spectra, recorded with a PerkinElmer machine (Attenuated Total Reflectance (ATR) mode) during 32 scans in the range of $4000-400 \mathrm{~cm}^{-1}$ at room temperature. X-ray Photon Spectroscopy (XPS) was carried out using a JEOL JPS9010 equipped with non-monochromatic $\mathrm{Al} \mathrm{K \alpha} \mathrm{X}$-rays at $12 \mathrm{kV}$ and $25 \mathrm{~mA}$. The binding energy of $\mathrm{N}_{1} \mathrm{~S}$ was recorded using $\mathrm{O} 1 \mathrm{~S}$ at $532.9 \mathrm{eV}$ as a reference to correct the position of spectra.

In order to evaluate the enantioselective recognition, the prepared electrodes were tested with $0.1 \mathrm{mM}$ of DL-tryptophan as a racemic solution in either acidic solution $(\mathrm{pH}-1-2)$ or basic solution $(\mathrm{pH} \sim 10-11)$ and with or without applied potential for 24 hours at $15^{\circ} \mathrm{C}$. Afterwards, the solution was analyzed by HPLC, performed on a Shimadzu LC2030C 3 D equipped with a chiral HPLC column (CHIROBIOTIC T, $25 \mathrm{~cm} \times 4.6 \mathrm{~mm}$ I.D., $5 \mu \mathrm{m}$ particles $(12024 \mathrm{AST}))$ using a mobile phase containing $70 \%$ methanol, $30 \%$ ultrapure water $(18.2 \mathrm{M} \Omega \cdot \mathrm{cm})$ and $0.02 \%$ formic acid at a flow rate of $1 \mathrm{~mL} / \mathrm{min}$ and an optical detection at $260 \mathrm{~nm}$. To study the effect of applied potential, a potential of $+0.75 \mathrm{~V}$ was applied during the adsorption experiment.

2.5. Enantioselective separation of chiral compounds with chiral macroporous MOFs surfaces 
In order to build the microfluidic channel, two electrodes, on which a narrow strip of chiral MOF (brown band in Figure S14A) has been synthesized by electrodeposition, were placed face to face by positioning double-sided tape along both sides of the chiral MOFs deposit. This leads to the configuration illustrated in the cross section scheme of Figure $\mathrm{S}_{14} \mathrm{C}$, where the two MOF deposits constitute the upper and lower wall of the microchannel, leaving an empty space in between, where the solution is able to flow (final channel dimensions of $0.2 \mathrm{~cm} \times 4.2 \mathrm{~cm} \times 0.8 \mu \mathrm{m})$. This channel was mounted in a microfluidic set-up with a Pt wire as pseudo-reference electrode placed at the exit of the microfluidic channel (Figure S14B). Various potentials were applied at the stationary phase (from o to $+0.75 \mathrm{~V}$ vs $\mathrm{Pt}$ ). During the experiment, $0.2 \mu \mathrm{L}$ of the racemate solution under basic conditions ( $\mathrm{pH}$ 10-11, adjusted by $\mathrm{KOH}$ ) was injected at the entrance of the microfluidic channel with a flow rate of $0.5 \mathrm{~mL} \mathrm{~h}^{-1}$. At the exit, the fluorescence of the molecules is detected by a spectrophotometer, connected to an optical fiber, using an excitation wavelength of $396 \mathrm{~nm}$ from a UV light-emitting diode.

\section{Results and discussion}

\subsection{Engineering and characterization of macroporous chiral ZIF-8}

For the electrochemical synthesis of hierarchical macroporous chiral ZIF-8, PS beads were used as colloidal crystal templates to generate a macroporous structure. The porous electrode has been successfully prepared by following the four steps illustrated in Scheme 1: i) electrophoretic assembly of PS beads on a Au coated glass slide to generate a colloidal crystal template; ii) Zn electrodeposition through the PS bead layer by electroreduction of $\mathrm{Zn}^{2+}$; iii) template dissolution to reveal the macroporous $\mathrm{Zn}$ structure; iv) transformation of the macroporous $\mathrm{Zn}$ electrode into chiral ZIF-8 via electrochemical dissolution of the metal in the presence of 2imidazolate as main ligand and D- or L-histidine as chiral ligands.

In order to optimize the conditions for $\mathrm{Zn}$ and ZIF-8 deposition (e.g., applied potential, concentration of the solution, deposition and dissolution times), all experiments were first performed with flat deposits, without using PS templates. As can be seen in Figure S1, the surface morphologies of electrodes obtained with two different electrodeposition methods are quite different. Steadystate deposition (Figures $\mathrm{S}_{1} \mathrm{~A}$ and $\mathrm{S} 1 \mathrm{~B}$ ) results in nonuniform surface structures. More homogeneous surfaces can be produced when using pulsed electrodeposition (Figures $\mathrm{S}_{1} \mathrm{C}$ and $\mathrm{S} 1 \mathrm{D}$ ). These observations relate to the fact that in the case of pulsed electrodeposition, applying the potential for a short time ( 5 seconds) followed by a relaxation period ( 20 seconds) prevents the formation of too strong $\mathrm{Zn}^{2+}$ concentration gradients at the electrode surface, thus avoiding the growth of dendrites.

In order to generate chiral ZIF-8, the deposited $\mathrm{Zn}$ was slowly electrooxidized at a potential of $-0.70 \mathrm{~V}$ vs $\mathrm{Ag} / \mathrm{AgCl}$ in the presence of the organic ligands. Obviously, the degree of MOF crystallization strongly depends on the used oxidation potential. It was found that dissolution at high potentials $(+0.30 \mathrm{~V}$ vs $\mathrm{Ag} / \mathrm{AgCl})$ is preferable for the dissolution of $\mathrm{Zn}$ and leads to the formation of smaller MOF crystallites (Figure $\mathrm{S}_{2} \mathrm{~A}$ ). In contrast, the dissolution rate at low potentials $(-0.70 \mathrm{~V}$ vs $\mathrm{Ag} / \mathrm{AgCl})$ is slower, eventually resulting in larger crystals (Figure $\mathrm{S}_{2} \mathrm{~B}$ ). Therefore, the latter condition is more suitable for the synthesis of chiral ZIF-8 with a very homogeneous crystal distribution on flat surfaces (Figure $\mathrm{S}_{3}$ ). For generating a macroporous chiral ZIF-8 structure, PS beads were assembled homogeneously on the Au electrode surface as macroporous template via electrophoretic deposition. Figure $1 \mathrm{~A}$ and Figure $1 \mathrm{~B}$ show the top and cross-sectional views, respectively, after deposition of the PS beads and heating at $80^{\circ} \mathrm{C}$ for $10 \mathrm{~min}$ in order to stabilize the PS beads on the electrode surface. Subsequently, Zn was deposited through the template via pulsed electroreduction of $\mathrm{Zn}^{2+}$. Then, the PS beads are removed using tetrahydrofuran (THF) to produce macroporous $\mathrm{Zn}$ as shown in Figures $2 \mathrm{~A}$ and $2 \mathrm{~B}$.

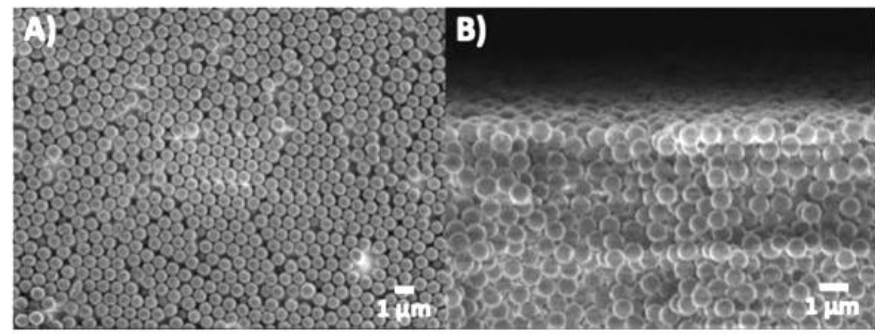

Figure 1 SEM images of the polystyrene bead arrangement on a Au coated glass-slide obtained by electrophoretic deposition: $A$ ) top view and $B$ ) cross-sectional view.

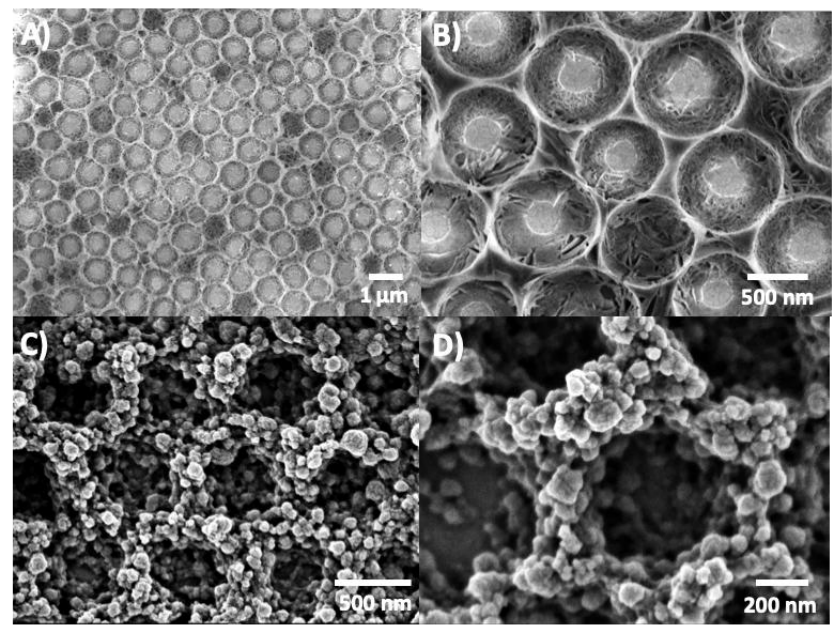

Figure 2 SEM images of A) a macroporous Zn electrode obtained with pulsed electrodeposition at an applied potential of $-1.08 \mathrm{~V}$ vs $\mathrm{Ag} / \mathrm{AgCl}$ (5 s pulses and $20 \mathrm{~s}$ relaxation time) at low magnification B) macroporous $\mathrm{Zn}$ at 
high magnification, C) hierarchical macroporous chiral ZIF-8 generated at $-0.7 \mathrm{~V}$ vs $\mathrm{Ag} / \mathrm{AgCl}$ in the ligand solution for 10 min at low magnification, and D) at high magnification.

The transformation of macroporous $\mathrm{Zn}$ into hierarchical chiral ZIF-8 is achieved by steady-state electroconversion at a potential of $-0.70 \mathrm{~V}$ (vs. $\mathrm{Ag} / \mathrm{AgCl}$ ) for $10 \mathrm{~min}$. During this step, $\mathrm{Zn}$ is oxidized to produce $\mathrm{Zn}^{2+}$ ions, which react with the ZIF-8 ligand and the histidine enantiomers at the electrode surfaces. By optimizing the molar ratio of ZIF-8 ligand to histidine from 90:10 to 80:20 and 70:30, it was found that for the latter two ratios it is impossible to obtain a homogeneous coverage of ZIF-8 on surface (Figure $\mathrm{S}_{4}$ ). This is due to the fact that a too low amount of intrinsic ligand does not allow the formation of the ZIF-8 lattice. Therefore, the most suitable ratio between the original ZIF-8 ligand and histidine as enantiomeric ligand should be 90:10. Under these optimized conditions, hierarchical macroporous chiral ZIF-8 was successfully obtained as shown in Figures $2 \mathrm{C}$ and $2 \mathrm{D}$. In order to confirm the ZIF- 8 crystal structure, the XRD patterns obtained from thin film measurements were analysed. They show the main characteristic peaks $(2 \Theta)$ at $7.4^{\circ}, 10.4^{\circ}, 12.7^{\circ}, 14.7^{\circ}, 16.4^{\circ}, 18.0^{\circ}$, corresponding to the indices of the (o11), (oo2), (112), (022), (013) and (222) crystal planes, respectively. ${ }^{67}$ These findings are very similar to what has been obtained with powder samples, but obviously the signal has a lower intensity due to the thin layer configuration (Figure $\mathrm{S}_{5}$ ). In addition, the physisorption results of hierarchical chiral D-His-ZIF-8 indicate a complete preservation of the microporosity $(1556 \mathrm{~m} 2 / \mathrm{g})$, similar to and slightly higher than the one of flat chiral D-His-ZIF-8 $(1482 \mathrm{~m} 2 / \mathrm{g})$. The external surface area also slightly increases as shown in Table S1 and Figure S6. This is expected, as the microporosity shouldn't change too much because it is still the same MOF. However, the accessibility of the porous structure is improved by the presence of the macropores, acting as diffusional channels.

In order to confirm that the chiral ligand is incorporated into the ZIF-8 framework, additional XPS and FTIR experiments were performed and the results are illustrated in Figures S7, S8 and S9, respectively. The XPS spectrum over the full range of binding energy is shown in Figure S7. The XPS N is data (Figures S8), indicate the presence of signals at $399 \mathrm{eV}, 400 \mathrm{eV}$, and $401 \mathrm{eV}$ corresponding to the characteristic peaks of imidazole $(=\mathrm{N}-)$ and imidazole- $\mathrm{NH}-$ of the original MOF ligand, as well as $-\mathrm{NH}_{2}$ referring to the functional group of histidine, respectively. In the case of the chiral MOF electrodes, the characteristic nitrogen signal of histidine $(401 \mathrm{eV})$ is present whereas in the achiral MOF it is absent. Furthermore, the deconvoluted XPS results ( $\mathrm{N}_{1 \mathrm{~S}}$ ) show that the peak intensity of $-\mathrm{NH}_{2}$ at $401.0 \mathrm{eV}$ is higher for macroporous MOF-L-His (Figure S8B) compared to flat MOF-L-His (Figure S8D), indicating the presence of a higher amount of chiral functions in the case of macroporous MOF-L-His. However, the obtained XPS data only prove the presence of histidine in the synthesized chiral MOF electrodes, but do not allow confirming the type of interaction with the framework. In order to distinguish between histidine which is just loosely present in the MOF pores and histidine which is really incorporated into the skeleton, FTIR measurements have been performed in addition. The results reveal that the $\mathrm{NH}$ vibration at $925 \mathrm{~cm}^{-1}$ which can be attributed to free histidine disappears for the histidine containing chiral MOF (Figure S9). In addition, FTIR results again confirm the presence of L-His at $1627 \mathrm{~cm}^{-1}$, corresponding to the stretching of the $\mathrm{C}=\mathrm{O}$ bond in the carboxy group of $\mathrm{L}-$ His. ${ }^{3}$ Combining these two independent and complementary pieces of information (presence of histidine, but no free amino group), it is reasonable to conclude that the histidine is incorporated into the MOF skeleton of the synthesized chiral MOF electrodes.

\subsection{Enantioselective adsorption}

The enantioselective adsorption on the designed surfaces was tested by exposing the hierarchical macroporous chiral ZIF-8 electrode to a racemic mixture of $\mathrm{L}-$ and D-tryptophan for a certain time. Then, the solution composition is analysed by HPLC equipped with a chiral stationary phase. The D/L tryptophan separation factor $\left(\alpha_{D / L}\right)$ was calculated as the quotient of the ratio of D-tryptophan to L- tryptophan concentrations in the solution, after and before being in contact with the electrode. Tryptophan has been chosen as adsorbate because of the possibility to establish noncovalent $\mathrm{N}-\mathrm{H}---\mathrm{O}=\mathrm{C}$ interactions between the guest amino acid and the chiral histidine. ${ }^{31,} 45$ Interestingly, the enantioselective adsorption is $\mathrm{pH}$ dependent, due to varying interactions between the chiral probe and the chiral ligand in the MOF (Table S2). Almost no enantioselective adsorption was observed at $\mathrm{pH} 7$, while at $\mathrm{pH} \sim 10-11$ the complete deprotonation of the amino acid allows much stronger electrostatic forces. The enantioselective adsorption at higher temperatures $\left(30^{\circ} \mathrm{C}\right)$ (Entry 5 Table S2) is less pronounced than at lower temperatures $\left(15^{\circ} \mathrm{C}\right)$ (Entry 3, Table S2). $\alpha_{\mathrm{D} / \mathrm{L}}$ of hierarchical macroporous ZIF-8 with Lhistidine as a chiral ligand is found to be 1.08. The opposite trend is seen when using an electrode coated with a MOF containing D-histidine. In this case $\alpha_{\mathrm{D} / \mathrm{L}}$ is 0.88 (Table 1, Entries 1 and 2), indicating discriminating interactions of chiral compounds with the two types of electrode surfaces. The adsorption results observed for L-HistidineZIF-8 and D-Histidine-ZIF-8 should be in theory completely symmetric. However, the ratio between the original 2-imidazole ligand and chiral histidine (L-Histidine or D-Histidine) is 9o:10. Therefore, during the synthesis of chiral ZIF-8, the content of incorporated histidine can fluctuate, and also the thickness of the final electrode layer can vary within certain limits. Therefore, for a given adsorption time more or less chiral probe gets trapped in the porous structure. Thus the absolute values are not the most important result in this context, but the change in the type of enantiomer which is preferentially adsorbed ( $\alpha_{D / L}>1$ and $\left.\alpha_{D / L}<1\right)$. In order to confirm the origin of the 
selective interaction between the chiral ligands (L- or Dhistidine) of the ZIF-8 structure and the chiral probes (Lor D-tryptophan), DFT calculations were performed. A significant difference in adsorption energy for L- and Dtryptophan on chiral ZIF-8 containing L-histidine ligands is observed (Table $\mathrm{S}_{3}$ ) and their interactions are illustrated in Figure Sio.

Table 1. The D/L tryptophan separation factor $\left(\alpha_{D / L}\right)$ calculated by integrating the respective HPLC peaks (in MilliQ water at $\mathrm{pH} \sim 10-11)$.

\begin{tabular}{|c|c|c|c|c|}
\hline Entry & $\begin{array}{c}\text { Structure } \\
\text { name }\end{array}$ & $\begin{array}{c}\text { Applied } \\
\text { potential } \\
(\mathbf{V})\end{array}$ & $\begin{array}{c}\text { Adsorption } \\
\text { time (h) }\end{array}$ & $\begin{array}{c}\boldsymbol{\alpha}_{\mathrm{D} / \mathrm{L}} \\
\mathbf{1}\end{array}$ \\
\hline $\mathbf{2}$ & $\begin{array}{c}\text { L- } \\
\text { Histidine- } \\
\text { ZIF-8 }\end{array}$ & - & 24 & 1.08 \\
\hline 3 & $\begin{array}{c}\text { D- } \\
\text { Histidine- } \\
\text { ZIF-8 }\end{array}$ & - & 24 & 0.88 \\
\hline 4 & $\begin{array}{c}\text { Histidine- } \\
\text { ZIF-8 }\end{array}$ & +0.75 & 24 & 1.47 \\
\hline $\begin{array}{c}\text { Histidine- } \\
\text { ZIF-8 }\end{array}$ & +0.75 & 24 & 0.38 \\
\hline
\end{tabular}

${ }^{\mathrm{a}}$ The separation was performed in bulk solution and measured by HPLC analysis.

${ }^{b}$ The $\mathrm{D} / \mathrm{L}$ Tryptophan separation factor $\left(\alpha_{\mathrm{D} / \mathrm{L}}\right)$ is calculated as the quotient of the ratios of D-Tryptophan to LTryptophan concentrations in the solution, after and before being in contact with the electrode for $24 \mathrm{~h}$.

In order to enhance the interaction between the enantiomers and the chiral MOF structures, the electrostatic attraction between the molecules and the surface can be fine-tuned by applying an optimized potential of $+0.75 \mathrm{~V}$ vs $\mathrm{Ag} / \mathrm{AgCl}$ to the electrode during the adsorption process, combined with an adjustment of the $\mathrm{pH}$ of the racemate solution. Tryptophan has a negative charge in basic solution ( $\mathrm{pH}$ 10-11). Adding these electrostatic interactions leads to a significant improvement of the enantioselective adsorption at the electrode surfaces (Table 1, Entries 3 and 4), also confirmed by the simulation results. When an electric field is integrated in the simulation, the adsorption energies are much higher, indicating a stronger selective interaction between L-tryptophan and chiral ZIF-8 containing L-histidine (Table $\mathrm{S}_{3}$ ). This is consistent with the results of the adsorption experiments. $\alpha_{D / L}$ increases to 1.47 when using chiral ZIF-8 with Lhistidine inclusions, whereas $\alpha_{\mathrm{D} / \mathrm{L}}$ is 0.38 , when using the MOF containing D-histidine ligands. This demonstrates that the binding affinity of tryptophan for chiral ZIF-8 can be significantly enhanced by controlling the electrostatic interactions.

In order to validate the more general applicability of these functional materials for chiral recognition, the enantioselective adsorption was not only tested for tryptophan, but also for another chiral molecule i.e. phenylalanine. As can be seen in Table S4, the L-Histidine-ZIF-8 structure is preferentially interacting with Dphenylalanine. On the contrary, the D-Histidine-ZIF-8 deposit has a stronger interaction with L-phenylalanine. This clearly indicates again that the MOF has intrinsic chiral features. However, at first sight rather surprisingly, in this case an opposite trend of affinity is obtained compared to tryptophan adsorption (preferential adsorption of $\mathrm{D}$ on $\mathrm{L}$ and not $\mathrm{D}$ on $\mathrm{D}$ ). In order to understand this phenomenon, we need to consider the three point interaction between the chiral ligand (L-histidine) of ZIF-8 and the chiral probe molecules (either tryptophan or phenylalanine enantiomers). Interestingly, different three-point interactions are possible in these two systems as shown in Figure S13. The amino group of the amino acid probe always interacts with the carboxyl group of the amino acid present in the MOF framework, and correspondingly also the carboxyl group of the probe with the amino group of the chiral constituent of the MOF. Therefore, this is a two-point interaction. However, the big difference between tryptophan and phenylalanine originates from the third interaction, which involves the heterocycles of histidine and tryptophan or the benzene ring of phenylalanine. The hydrophilic nitrogen groups present in the histidine ring interact in a favorable way with the equally hydrophilic nitrogen group present in the heterocycle of tryptophan. The situation is different for phenylalanine where the hydrophobic benzene ring doesn't like to be positioned close to the hydrophilic heterocycle of histidine. Therefore, the opposite enantiomeric conformation of phenylalanine, where at the asymmetric carbon atom the benzene ring exchanges position with the hydrogen atom, has a more favorable interaction with the histidine molecule. These additional results clearly indicate that not only tryptophan but also other molecules, such as phenylalanine, show enantioselective interactions with the chiral MOF phase.

The ZIF-8 structure is not destroyed under the conditions used in the experiments described above, as has been verified by XRD of powder ZIF-8 (Figure Si1). It was found that the crystalline structure of ZIF- 8 can be preserved in basic solutions ( $\mathrm{pH} \sim 10-11)$ as illustrated by SEM and EDS mapping in Figure S12. However, it is well-known that in general MOF structures are rather sensitive to either acidic or basic conditions. As expected, when exposing the MOF structure to high or low $\mathrm{pH}$ solutions for prolonged periods of time, a degradation of the MOF is revealed by XRD measurements (Figure S11). However, this degradation occurs over a time scale $(48 \mathrm{~h})$ which is much longer than the time scale of the adsorption and separation experiments. 


\subsection{Enantioselective separation}

The advantage of hierarchical macroporous chiral ZIF-8 is, as demonstrated above, the preferential adsorption of one enantiomer of a racemate solution. This feature can be further exploited by using the functional material as stationary phase in a microchannel device for chiral separation (Scheme 2 and Figure S14).

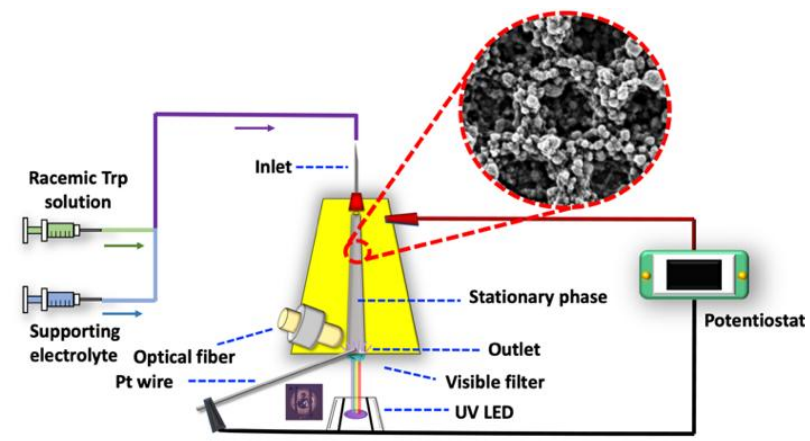

Scheme 2 Illustration of the electrochromatographic separation using a microfluid device containing hierarchical chiral ZIF-8 in the channel, equipped with a fluorescence detector and a potentiostat for potential control of the stationary phase.

Recently, we described the concept of introducing a chiral imprinted metal film as stationary phase deposited in a microfluidic channel. ${ }^{29}$ Fine-tuning the binding affinity eventually leads to a complete baseline separation of racemic mixtures. ${ }^{29}$ In a similar separation scheme the macroporous chiral ZIF-8 can be also employed as a stationary phase, combined with an injection system and fluorescence detector to characterize the separation capability. Based on the above-mentioned controllable enantioselective interaction between tryptophan and the chiral host material, this allows discrimination of the two enantiomers. In order to identify the most suitable conditions for the separation, the microfluidic channel was connected with an injector, ensuring a mobile phase flow rate of $0.5 \mathrm{~mL} \mathrm{~h}^{-1}$, and a spectrophotometer as the fluorescence detector with an excitation wavelength of 396 nm from a UV light-emitting diode. In addition, a Pt wire was used as a counter and pseudo-reference electrode at the channel outlet. While injecting the racemate solution into the channel, a potential ranging from o to $+1 \mathrm{~V}$ vs $\mathrm{Pt}$ wire was applied to the stationary phase. Without applied potential, a single peak was observed, indicating a very weak interaction of the enantiomers with the stationary phase (Figure $3 \mathrm{~A}$ ). In contrast to this, a broad signal composed of two peaks can be observed when applying +0.25 $\mathrm{V}$ (Figure $3 \mathrm{~B}$ ), due to a stronger interaction between the MOF structure and the negatively charged racemate molecules. Interestingly, at an even higher positive potential (Figure $3 \mathrm{C}$ ), the electrochromatogram of L-tryptophan and D-tryptophan shows a further improved separation. In particular, when applying +0.75 $\mathrm{V}$, two distinct peaks appear, although not completely baseline separated (Figure $3 \mathrm{D})$. However, when applying a too high positive potential $(+1 \mathrm{~V})$, the peak separation becomes less evident, most likely because the stationary phase gets damaged at very high positive potentials (Figure S15). Therefore, $+0.75 \mathrm{~V}$ seems to be the most suitable potential allowing an optimized interaction between the chiral compounds and the stationary phase.
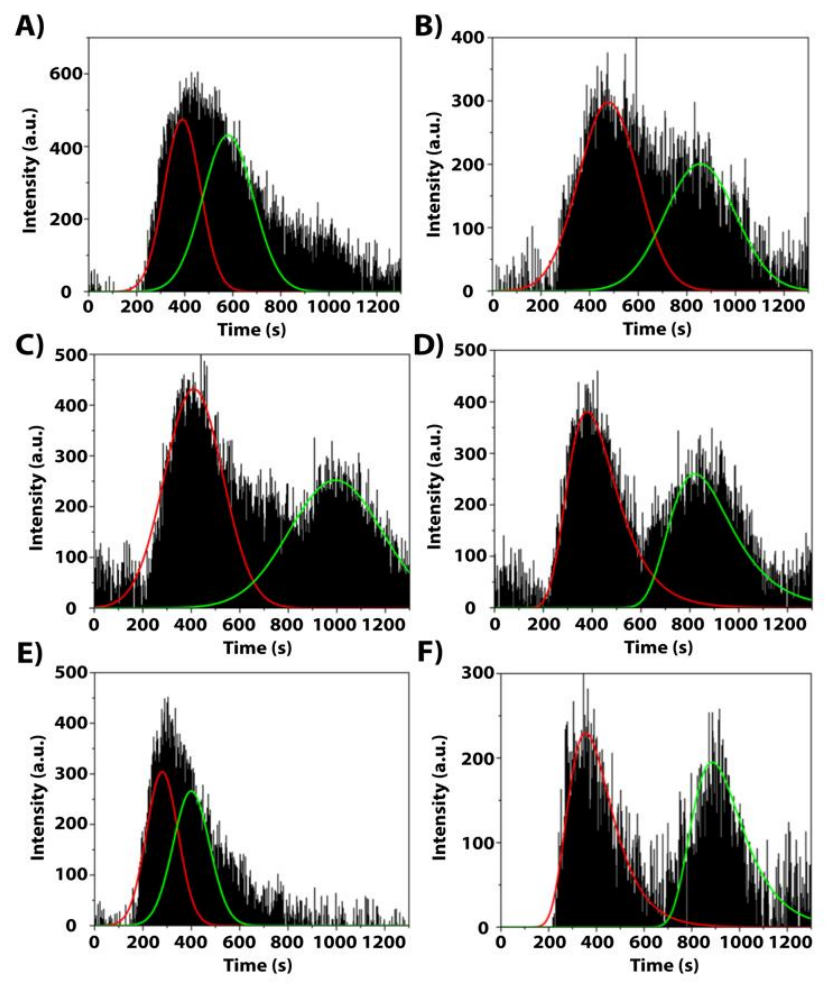

Figure 3 Fluorescence signals of tryptophan using an excitation wavelength of $396 \mathrm{~nm}$ from a UV lightemitting diode recorded with an optical fiber at the outlet of the microfluidic channel modified with flat chiral DHis-ZIF-8 A) no applied potential, B) $+0.25 \mathrm{~V}$ vs Pt wire applied to the stationary MOF phase, C) $+0.50 \mathrm{~V}, \mathrm{D})$ $+0.75 \mathrm{~V}$ E) Hierarchical chiral D-His-ZIF-8 as stationary phase with no applied potential, and F) +0.75V vs Pt wire. Red and green lines indicate the deconvoluted peaks of Ltryptophan and D-tryptophan respectively.

The beneficial effect of hierarchical macroporous chiral ZIF-8 is illustrated by the fact that when it is used instead of flat MOF with an applied potential of $+0.75 \mathrm{~V}$ the electrochromatogram shows now complete baseline separation and peaks are sharper (Figure ${ }_{3} \mathrm{~F}$ ). As expected, completely overlapping peaks of the two enantiomers are observed when no potential is applied (Figure $3 \mathrm{E}$ ). In order to confirm the specific retention times of $\mathrm{L}-$ tryptophan and D-tryptophan, the individual enantiomers were injected separately. Figures S16A and S16B illustrate that L-tryptophan and D-tryptophan appear at 
retention times of around 300 and 8oos, respectively, but slight variations can occur due to fluctuations in the flow rate. These results confirm that D-tryptophan has a significantly stronger interaction with hierarchical D-HisZIF-8 compared to L-tryptophan.

In order to investigate the stability of the macroporous structure under microfluidic conditions, the same device was reused for a sequence of several separation experiments (Figure $\mathrm{S}_{17}$ ). The results obtained after ten runs over a period of 30 days indicate that the separation performance decreases, but two peaks can still be identified. We attribute this decrease in performance to a partial loss of MOF, being slowly washed out from the microchannel due to the existing backpressure. However, in the future this can be minimized by adjusting and optimizing the experimental parameters, such as the injection pressure, the flow rate and the thickness of the MOF layers. Finally, a control experiment has been performed to confirm the crucial role of the MOF inside microfluid channel. A racemic solution of tryptophan was injected into the empty microfluidic device without the MOF decorating the channel walls. This blank experiment was carried out with and without applied potential (Figure $\mathrm{S} 18$ ). As expected, there is no visible separation in both cases, confirming the absence of enantiospecific interactions between the tryptophan molecules and the channel environment.

\section{Conclusions}

Hierarchically structured chiral MOF has been successfully synthesized as a functional material via an electrochemical deposition-dissolution approach, using a colloidal crystal as a template to generate macropores in addition to the intrinsically present micropores. The chiral MOF can be generated by introducing chiral ligands into the framework during the controlled electrooxidation of the metal. To illustrate the benefits of the prepared chiral material, it was used for enantioselective adsorption and separation experiments. Compared with flat chiral MOF, the effect of the chirality is amplified by the macroporous structure due to the presence of a higher and better accessible number of adsorption sites. In addition, the binding affinity of the designed MOF surfaces can be fine-tuned by applying a suitable potential. Hence, this work opens up interesting perspectives for the development of a new class of chiral surfaces based on the combination of macroporous structures together with chiral building blocks and the concept might serve for several chiral technology applications, ranging from adsorption and separation to catalysis.

\section{ASSOCIATED CONTENT}

\section{Supporting Information}

The Supporting Information is available free of charge on the ACS Publications website.
Details of DFT calculations; Additional characterization of samples by SEM, XRD, XPS, EDS, FTIR and adsorption isotherms; Control experiments; Tables with additional experimental data and simulation results; Schemes with molecular structures

\section{AUTHOR INFORMATION}

\section{Corresponding Author}

Chularat Wattanakit

E-mail: Chularat.w@vistec.ac.th

School of Energy Science and Engineering, Vidyasirimedhi Institute of Science and Technology, Rayong 21210, Thailand

\section{Alexander Kuhn \\ E-mail: kuhn@enscbp.fr \\ University Bordeaux, ISM, CNRS UMR 5255, Bordeaux INP, Site ENSCBP, Pessac, France}

\section{Present Addresses}

${ }^{\dagger}$ School of Energy Science and Engineering, School of Molecular Science and Engineering, and Nanocatalysts and Nanomaterials for Sustainable Energy and Environment Research Network of NANOTEC, Vidyasirimedhi Institute of Science and Technology, Rayong 21210, Thailand

*University Bordeaux, ISM, CNRS UMR 5255, Bordeaux INP, Site ENSCBP, Pessac, France

${ }^{\S}$ Department of Chemistry, Faculty of Liberal Arts and Science, Kasetsart University, Kamphaeng Saen Campus, Nakhon Pathom 73140, Thailand

\section{Author Contributions}

D.S., A.K., and C.W. conceived and designed the experiments; D.S., S.B., S.A. and B.G. performed the experiments; T.M., A.P., and N.S. contributed to the characterization techniques; D.S., A.K., and C.W. co-produced the manuscript.

\section{Funding Sources}

- Thailand Research Fund (TRF) (MRG6180099)

- European Research Council (ERC) under the European Union's Horizon 2020 research and innovation program (grant agreement no 741251, ERC Advanced grant ELECTRA)

\section{ACKNOWLEDGMENT}

We would like to acknowledge a grant from Vidyasirimedhi Institute of Science and Technology (VISTEC). We are grateful for very skillful help and advice from Dr. Thittaya Yutthalekha, Dr. Stéphane Reculusa, Dr. Somlak Ittisanronnachai, and Mr. Teerapat Lapsirivatkul. This work was supported by the bilateral French-Thai PICS program of CNRS. Chu. W. thanks the Thailand Research Fund (TRF) (MRG6180099), the Office of Higher Education Commission (OHEC) and TTSF research project supported 
by Thailand Toray Science Foundation. In addition, this work has been partially supported by the National Nanotechnology Center (NANOTEC), NSTDA, Ministry of Science and Technology, Thailand, through its Research Network NANOTEC (RNN). The project has also been partially funded by the European Research Council (ERC) under the European Union's Horizon 2020 research and innovation program (grant agreement no 741251, ERC Advanced grant ELECTRA).

\section{ABBREVIATIONS}

ZIF-8, Zeolitic Imidazolate Framework-8; MOFs, Metalorganic frameworks; $\mathrm{ZnBLD}, \mathrm{Zn}_{2}$ (bdc)(L-lac)(dmf); bdc, 1,4benzenedicarboxylic acid; L-lac, L-lactic acid; dmf, N,N' dimethylformamide); HKUST-1, Hong Kong University of Science and Technology-1; PS, Polystyrene; MOF-L-His, Metal-organic frameworks incorporating L-Histidine

\section{REFERENCES}

(1) Smith, S. W. Chiral Toxicology: It's the Same Thing...Only Different. Toxicol. Sci. 2009, 110, 4-30.

(2) Ma, L.; Falkowski, J. M.; Abney, C.; Lin, W. A series of isoreticular chiral metal-organic frameworks as a tunable platform for asymmetric catalysis. Nat. Chem. 2010, 2, 838-846.

(3) Das, S.; Xu, S.; Ben, T.; Qiu, S. Chiral Recognition and Separation by Chirality-Enriched Metal-Organic Frameworks. Angew. Chem. Int. Ed. 2018, 57, 8629-8633.

(4) Seo, J. S.; Whang, D.; Lee, H.; Jun, S. I.; Oh, J.; Jeon, Y. J.; Kim, K. A homochiral metal-organic porous material for enantioselective separation and catalysis. Nature 2000, 404 982-986.

(5) Gübitz, G.; Schmid, M. G. Chiral separation by capillary electromigration techniques. J. Chromatogr. A 2008, 1204, 140-156.

(6) Ward, T. J.; Ward, K. D. Chiral Separations: Fundamental Review 2010. Anal. Chem. 2010, 82, 4712-4722.

(7) Schweitz, L.; Andersson, L. I.; Nilsson, S. Capillary Electrochromatography with Predetermined Selectivity Obtained through Molecular Imprinting. Anal. Chem. 1997, 69, $1179-1183$.

(8) Kempe, M.; Mosbach, K. Separation of amino acids, peptides and proteins on molecularly imprinted stationary phases. J. Chromatogr. A 1995, 691, 317-323.

(9) Maier, N. M.; Franco, P.; Lindner, W. Separation of enantiomers: needs, challenges, perspectives. J. Chromatogr. A 2001, 906, 3-33.

(10) Wattanakit, C.; Côme, Y. B. S.; Lapeyre, V.; Bopp, P. A.; Heim, M.; Yadnum, S.; Nokbin, S.; Warakulwit, C.; Limtrakul, J.; Kuhn, A. Enantioselective recognition at mesoporous chiral metal surfaces. Nat. Commun. 2014, 5, 3325.

(11) Corella-Ochoa, M. N.; Tapia, J. B.; Rubin, H. N.; Lillo, V.; González-Cobos, J.; Núñez-Rico, J. L.; Balestra, S. R. G.; Almora-Barrios, N.; Lledós, M.; Güell-Bara, A.; CabezasGiménez, J.; Escudero-Adán, E. C.; Vidal-Ferran, A.; Calero, S.; Reynolds, M.; Martí-Gastaldo, C.; Galán-Mascarós, J. R. Homochiral Metal-Organic Frameworks for Enantioselective Separations in Liquid Chromatography. J. Am. Chem. Soc. 2019, 141, 14306-14316.

(12) Sun, B.; Kim, Y.; Wang, Y.; Wang, H.; Kim, J.; Liu, X.; Lee, $M$. Homochiral porous nanosheets for enantiomer sieving. Nat. Mater. 2018, 17, 599-604.

(13) Navarro-Sánchez, J.; Argente-García, A. I.; MolinerMartínez, Y.; Roca-Sanjuán, D.; Antypov, D.; Campíns-Falcó, P.; Rosseinsky, M. J.; Martí-Gastaldo, C. Peptide MetalOrganic Frameworks for Enantioselective Separation of Chiral Drugs. J. Am. Chem. Soc. 2017, 139, 4294-4297.
(14) Han, X.; Huang, J.; Yuan, C.; Liu, Y.; Cui, Y. Chiral 3D Covalent Organic Frameworks for High Performance Liquid Chromatographic Enantioseparation. J. Am. Chem. Soc. 2018, 140, 892-895.

(15) Zhang, S.; Zheng, Y.; An, H.; Aguila, B.; Yang, C.-X.; Dong, Y.; Xie, W.; Cheng, P.; Zhang, Z.; Chen, Y.; Ma, S. Covalent Organic Frameworks with Chirality Enriched by Biomolecules for Efficient Chiral Separation. Angew. Chem. Int. Ed. 2018, 57, 16754-16759.

(16) Chan, J. Y.; Zhang, H.; Nolvachai, Y.; Hu, Y.; Zhu, H.; Forsyth, M.; Gu, Q.; Hoke, D. E.; Zhang, X.; Marriot, P. J.; Wang, $H$. Incorporation of Homochirality into a Zeolitic Imidazolate Framework Membrane for Efficient Chiral Separation. Angew. Chem. Int. Ed. 2018, 57, 17130-17134.

(17) Switzer, J. A.; Kothari, H. M.; Poizot, P.; Nakanishi, S.; Bohannan, E. W. Enantiospecific electrodeposition of a chiral catalyst. Nature 2003, 425, 490-493.

(18) Barlow, S. M.; Raval, R. Complex organic molecules at metal surfaces: bonding, organisation and chirality. Surf. Sci. Rep. 2003, 50, 201-341.

(19) Humblot, V.; Lorenzo, M. O.; Baddeley, C. J.; Haq, S.; Raval, R. Local and Global Chirality at Surfaces: Succinic Acid versus Tartaric Acid on Cu(110). J. Am. Chem. Soc. 2004, 126, 6460-6469.

(20) Ohmann, R.; Levita, G.; Vitali, L.; De Vita, A.; Kern, K. Influence of Subsurface Layers on the Adsorption of Large Organic Molecules on Close-Packed Metal Surfaces. ACS Nano 2011, 5, 1360-1365.

(21) Lorenzo, M. O.; Haq, S.; Bertrams, T.; Murray, P.; Raval, R.; Baddeley, C. J. Creating Chiral Surfaces for Enantioselective Heterogeneous Catalysis: R,R-Tartaric Acid on $\mathrm{Cu}(110)$. J. Phys. Chem. B 1999, 103, 10661-10669.

(22) Gross, E.; Liu, J. H.; Alayoglu, S.; Marcus, M. A.; Fakra, S. C.; Toste, F. D.; Somorjai, G. A. Asymmetric Catalysis at the Mesoscale: Gold Nanoclusters Embedded in Chiral SelfAssembled Monolayer as Heterogeneous Catalyst for Asymmetric Reactions. J. Am. Chem. Soc. 2013, 135, 3881-3886.

(23) Attard, G. A. Electrochemical Studies of Enantioselectivity at Chiral Metal Surfaces. J. Phys. Chem. B 2001, 105, 31583167.

(24) Hazzazi, O. A.; Attard, G. A.; Wells, P. B. Molecular recognition in adsorption and electro-oxidation at chiral platinum surfaces. J. Mol. Catal. A: Chem. 2004, 216, 247-255.

(25) Sholl, D. S.; Asthagiri, A.; Power, T. D. Naturally Chiral Metal Surfaces as Enantiospecific Adsorbents. J. Phys. Chem. B 2001, 105, 4771-4782.

(26) Durán Pachón, L.; Yosef, I.; Markus, T. Z.; Naaman, R.; Avnir, D.; Rothenberg, G. Chiral imprinting of palladium with cinchona alkaloids. Nat. Chem. 2009, 1, 160-164.

(27) Yutthalekha, T.; Wattanakit, C.; Lapeyre, V.; Nokbin, S.; Warakulwit, C.; Limtrakul, J.; Kuhn, A. Asymmetric synthesis using chiral-encoded metal. Nat. Commun. 2016, 7, 12678.

(28) Wattanakit, C.; Yutthalekha, T.; Asssavapanumat, S.; Lapeyre, V.; Kuhn, A. Pulsed electroconversion for highly selective enantiomer synthesis. Nat. Commun. 2017, 8, 2087.

(29) Assavapanumat, S.; Yutthalekha, T.; Garrigue, P.; Goudeau, B.; Lapeyre, V.; Perro, A.; Sojic, N.; Wattanakit, C.; Kuhn, A. Potential-Induced Fine-Tuning of the Enantioaffinity of Chiral Metal Phases. Angew. Chem. Int. Ed. 2019, 58, 34713475.

(30) Assavapanumat, S.; Gupta, B.; Salinas, G.; Goudeau, B.; Wattanakit, C.; Kuhn, A. Chiral platinum-polypyrrole hybrid films as efficient enantioselective actuators. Chem. Commun. 2019, 55, 10956-10959.

(31) Zhao, J.; Li, H.; Han, Y.; Li, R.; Ding, X.; Feng, X.; Wang, B. Chirality from substitution: enantiomer separation via a modified metal-organic framework. J. Mater. Chem. A 2015, 3, 12145-12148.

(32) Hendon, C. H.; Rieth, A. J.; Korzyński, M. D.; Dincă, M. Grand Challenges and Future Opportunities for Metal-Organic Frameworks. ACS Central Science 2017, 3, 554-563. 
(33) Furukawa, H.; Cordova, K. E.; O’Keeffe, M.; Yaghi, O. M. The Chemistry and Applications of Metal-Organic Frameworks. Science 2013, 341, $1230444-1230456$.

(34) Banerjee, R.; Furukawa, H.; Britt, D.; Knobler, C.; O'Keeffe, M.; Yaghi, O. M. Control of Pore Size and Functionality in Isoreticular Zeolitic Imidazolate Frameworks and their Carbon Dioxide Selective Capture Properties. J. Am. Chem. Soc. 2009, 131, 3875-3877.

(35) Kitagawa, S.; Kitaura, R.; Noro, S.-i. Functional Porous Coordination Polymers. Angew. Chem. Int. Ed. 2004, 43, 23342375.

(36) Yaghi, O. M.; O'Keeffe, M.; Ockwig, N. W.; Chae, H. K.; Eddaoudi, M.; Kim, J. Reticular synthesis and the design of new materials. Nature 2003, 423, 705-714.

(37) Eddaoudi, M.; Kim, J.; Rosi, N.; Vodak, D.; Wachter, J.; Keeffe, M.; Yaghi, O. M. Systematic Design of Pore Size and Functionality in Isoreticular MOFs and Their Application in Methane Storage. Science 2002, 295, 469-472.

(38) Lee, J.; Farha, O. K.; Roberts, J.; Scheidt, K. A.; Nguyen, S. T.; Hupp, J. T. Metal-organic framework materials as catalysts. Chem. Soc. Rev. 2009, 38, 1450-1459.

(39) Li, H.; Eddaoudi, M.; O'Keeffe, M.; Yaghi, O. M. Design and synthesis of an exceptionally stable and highly porous metal-organic framework. Nature 1999, 402, 276-279.

(40) Achmann, S.; Hagen, G.; Kita, J.; Malkowsky, I. M.; Kiener, C.; Moos, R. Metal-organic frameworks for sensing applications in the gas phase. Sensors (Basel, Switzerland) 2009, 9, 1574-1589.

(41) Gole, B.; Sanyal, U.; Banerjee, R.; Mukherjee, P. S. High Loading of $\mathrm{Pd}$ Nanoparticles by Interior Functionalization of MOFs for Heterogeneous Catalysis. Inorg. Chem. 2016, 55, 2345-2354.

(42) Cui, Y.; Song, R.; Yu, J.; Liu, M.; Wang, Z.; Wu, C.; Yang, Y.; Wang, Z.; Chen, B.; Qian, G. Dual-Emitting MOFدDye Composite for Ratiometric Temperature Sensing. Adv. Mater. 2015, 27, 1420-1425.

(43) Chen, B.; Xiang, S.; Qian, G. Metal-Organic Frameworks with Functional Pores for Recognition of Small Molecules. Acc. Chem. Res. 2010, 43, 1115-1124.

(44) Stavila, V.; Talin, A. A.; Allendorf, M. D. MOF-based electronic and opto-electronic devices. Chem. Soc. Rev. 2014, 43, 5994-6010.

(45) Li, J.-R.; Kuppler, R. J.; Zhou, H.-C. Selective gas adsorption and separation in metal-organic frameworks. Chem. Soc. Rev. 2009, 38, 1477-1504.

(46) Al-Janabi, N.; Hill, P.; Torrente-Murciano, L.; Garforth, A.; Gorgojo, P.; Siperstein, F.; Fan, X. Mapping the Cu-BTC metal-organic framework (HKUST-1) stability envelope in the presence of water vapour for $\mathrm{CO}_{2}$ adsorption from flue gases. Chem. Eng. J. 2015, 281, 669-677.

(47) Dhainaut, J.; Bonneau, M.; Ueoka, R.; Kanamori, K.; Furukawa, S. Formulation of Metal-Organic Framework Inks for the 3D Printing of Robust Microporous Solids toward HighPressure Gas Storage and Separation. ACS Appl. Mater. Interfaces 2020, 12, 10983-10992.

(48) Liu, Z.; Zhu, J.; Peng, C.; Wakihara, T.; Okubo, T. Continuous flow synthesis of ordered porous materials: from zeolites to metal-organic frameworks and mesoporous silica. Reaction Chemistry \& Engineering 2019, 4, 1699-1720.

(49) Xu, S.; Chansai, S.; Stere, C.; Inceesungvorn, B.; Goguet, A.; Wangkawong, K.; Taylor, S. F. R.; Al-Janabi, N.; Hardacre, C.; Martin, P. A.; Fan, X. Sustaining metal-organic frameworks for water-gas shift catalysis by non-thermal plasma. Nature Catalysis 2019, 2, 142-148.

(50) Slater, B.; Wang, Z.; Jiang, S.; Hill, M. R.; Ladewig, B. P. Missing Linker Defects in a Homochiral Metal-Organic Framework: Tuning the Chiral Separation Capacity. J. Am. Chem. Soc. 2017, 139, 18322-18327.
(51) Li, W.; Wu, X.; Han, N.; Chen, J.; Qian, X.; Deng, Y.; Tang, W.; Chen, Y. MOF-derived hierarchical hollow ZnO nanocages with enhanced low-concentration VOCs gas-sensing performance. Sens. Actuators B Chem. 2016, 225, 158-166.

(52) Chaudhari, A. K.; Han, I.; Tan, J.-C. Multifunctional Supramolecular Hybrid Materials Constructed from Hierarchical Self-Ordering of In Situ Generated Metal-Organic Framework (MOF) Nanoparticles. Adv. Mater. 2015, 27, 4438-4446.

(53) Zhang, Z.; Chen, Y.; He, S.; Zhang, J.; Xu, X.; Yang, Y.; Nosheen, F.; Saleem, F.; He, W.; Wang, X. Hierarchical Zn/NiMOF-2 Nanosheet-Assembled Hollow Nanocubes for Multicomponent Catalytic Reactions. Angew. Chem. Int. Ed. 2014, 53, 12517-12521.

(54) Shen, K.; Zhang, L.; Chen, X.; Liu, L.; Zhang, D.; Han, Y.; Chen, J.; Long, J.; Luque, R.; Li, Y.; Chen, B. Ordered macromicroporous metal-organic framework single crystals. Science 2018, 359, 206-210.

(55) Meek, S. T.; Greathouse, J. A.; Allendorf, M. D. MetalOrganic Frameworks: A Rapidly Growing Class of Versatile Nanoporous Materials. Adv. Mater. 2011, 23, 249-267.

(56) Chen, Y.; Ni, D.; Yang, X.; Liu, C.; Yin, J.; Cai, K. Microwave-assisted synthesis of honeycomblike hierarchical spherical $\mathrm{Zn}$-doped Ni-MOF as a high-performance battery-type supercapacitor electrode material. Electrochim. Acta 2018, 278, 114-123.

(57) Vakili, R.; Xu, S.; Al-Janabi, N.; Gorgojo, P.; Holmes, S. M.; Fan, X. Microwave-assisted synthesis of zirconium-based metal organic frameworks (MOFs): Optimization and gas adsorption. Microporous Mesoporous Mater. 2018, 260, 45-53.

(58) Warakulwit, C.; Yadnum, S.; Boonyuen, C.; Wattanakit, C.; Karajic, A.; Garrigue, P.; Mano, N.; Bradshaw, D.; Limtrakul, J.; Kuhn, A. Elaboration of metal organic framework hybrid materials with hierarchical porosity by electrochemical depositiondissolution. CrystEngComm 2016, 18, 5095-5100.

(59) Li, X.; Chang, C.; Wang, X.; Bai, Y.; Liu, H. Applications of homochiral metal-organic frameworks in enantioselective adsorption and chromatography separation. Electrophoresis 2014, $35,2733-2743$.

(60) Al-Kutubi, H.; Gascon, J.; Sudhölter, E. J. R.; Rassaei, L. Electrosynthesis of Metal-Organic Frameworks: Challenges and Opportunities. ChemElectroChem 2015, 2, 462-474.

(61) Yadnum, S.; Roche, J.; Lebraud, E.; Négrier, P.; Garrigue, P.; Bradshaw, D.; Warakulwit, C.; Limtrakul, J.; Kuhn, A. SiteSelective Synthesis of Janus-type Metal-Organic Framework Composites. Angew. Chem. Int. Ed. 2014, 53, 4001-4005.

(62) Xie, S.-M.; Zhang, M.; Fei, Z.-X.; Yuan, L.-M. Experimental comparison of chiral metal-organic framework used as stationary phase in chromatography. J. Chromatogr. A 2014, 1363, 137-143.

(63) Fei, Z.-X.; Zhang, M.; Zhang, J.-H.; Yuan, L.-M. Chiral metal-organic framework used as stationary phases for capillary electrochromatography. Anal. Chim. Acta 2014, 830, 4955.

(64) Zhu, C.; Xia, Q.; Chen, X.; Liu, Y.; Du, X.; Cui, Y. Chiral Metal-Organic Framework as a Platform for Cooperative Catalysis in Asymmetric Cyanosilylation of Aldehydes. ACS Catal. 2016, 6, 7590-7596.

(65) Lu, G.; Hupp, J. T. Metal-Organic Frameworks as Sensors: A ZIF-8 Based Fabry-Pérot Device as a Selective Sensor for Chemical Vapors and Gases. J. Am. Chem. Soc. 2010, 132, 7832-7833.

(66) Pan, Y.; Liu, Y.; Zeng, G.; Zhao, L.; Lai, Z. Rapid synthesis of zeolitic imidazolate framework-8 (ZIF-8) nanocrystals in an aqueous system. Chem. Commun. 2011, 47, 2071-2073.

(67) Zhou, K.; Mousavi, B.; Luo, Z.; Phatanasri, S.; Chaemchuen, S.; Verpoort, F. Characterization and properties 
of $\mathrm{Zn} / \mathrm{Co}$ zeolitic imidazolate frameworks vs. ZIF-8 and ZIF-67. J. Mater. Chem. A 2017, 5, 952-957. 
Table of Contents

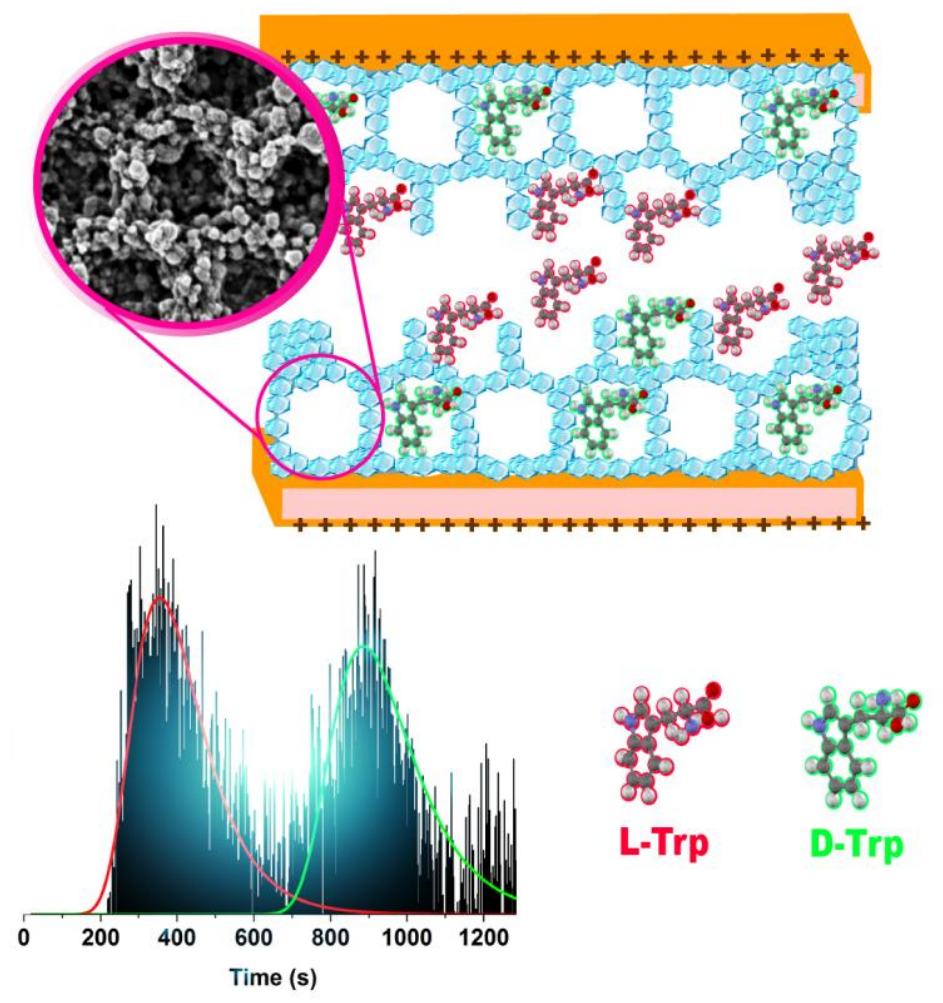

